\title{
Effects of a natural precipitation gradient on fish and macroinvertebrate assemblages in coastal streams
}

\author{
Sean Kinard ${ }^{\text {Corresp., } 1}$, Christopher J Patrick ${ }^{1}$, Fernando Carvallo ${ }^{2}$ \\ 1 Department of Biological Sciences, Virginia Institute of Marine Science, Gloucester Point, Virginia, United States of America \\ 2 Department of Life Sciences, Texas A\&M Corpus Christi, Corpus Christi, Texas, United States of America \\ Corresponding Author: Sean Kinard \\ Email address: skkinard@vims.edu
}

Anthropogenic climate change is expected to increase the aridity of many regions of the world. Surface water ecosystems are particularly vulnerable to changes in the water-cycle and may suffer adverse impacts in affected regions. To enhance our understanding of how freshwater communities will respond to predicted shifts in water-cycle dynamics, we employed a space for time approach along a natural precipitation gradient on the Texas Coastal Prairie. In the Spring of 2017, we conducted surveys of 10 USGS-gauged, wadeable streams spanning a semi-arid to sub-humid rainfall gradient; we measured nutrients, water chemistry, habitat characteristics, benthic macroinvertebrates, and fish communities. Fish diversity correlated positively with precipitation and was negatively correlated with conductivity. Macroinvertebrate diversity peaked within the middle of the gradient. Semiarid fish and invertebrate communities were dominated by euryhaline and live-bearing taxa. Sub-humid communities contained environmentally sensitive trichopterans and ephemeropterans as well as a variety of predatory fish which may impose top-down controls on primary consumers. These results warn that aridification coincides with the loss of competitive and environmentally sensitive taxa which could yield less desirable community states. 


\author{
Manuscript Title \\ Effects of a natural precipitation gradient on fish and macroinvertebrate assemblages in \\ coastal streams \\ Sean Kinard ${ }^{1}$, Christopher Patrick ${ }^{1}$, Fernando Carvallo ${ }^{2}$ \\ 1. Virginia Institute of Marine Science \\ 1370 Greate Road, Gloucester Point, Virginia 23062-1346 \\ 2. Texas A\&M Corpus Christi \\ 6300 Ocean Dr, Corpus Christi, TX 78412
}

\author{
Corresponding Author: \\ Sean Kinard ${ }^{1}$ \\ 6528 Quail Hollow Dr, Hayes VA 23072, USA \\ Email address: skkinard@vims.edu
}

\title{
Abstract:
}

Anthropogenic climate change is expected to increase the aridity of many regions of the world. Surface water ecosystems are particularly vulnerable to changes in the watercycle and may suffer adverse impacts in affected regions. To enhance our understanding of how freshwater communities will respond to predicted shifts in watercycle dynamics, we employed a space for time approach along a natural precipitation gradient on the Texas Coastal Prairie. In the Spring of 2017, we conducted surveys of 10 USGS-gauged, wadeable streams spanning a semi-arid to sub-humid rainfall gradient; we measured nutrients, water chemistry, habitat characteristics, benthic macroinvertebrates, and fish communities. Fish diversity correlated positively with precipitation and was negatively correlated with conductivity. Macroinvertebrate diversity peaked within the middle of the gradient. Semi-arid fish and invertebrate communities were dominated by euryhaline and live-bearing taxa. Sub-humid communities contained environmentally sensitive trichopterans and ephemeropterans as well as a variety of predatory fish which may impose top-down controls on primary consumers. These results warn that aridification coincides with the loss of competitive and environmentally sensitive taxa which could yield less desirable community states.

\section{Introduction:}

A warming climate warrants a better understanding of the processes that link biological communities to long-term trends in temperature and precipitation (Wrona et al. 2006; Miranda et al. 2020). The direct ecological effects of changes in temperature have received greater attention in the literature, but rising temperatures are also expected to alter patterns of precipitation and evaporation. A warmer, more energetic atmosphere intensifies the hydrological cycle (patterns of precipitation and evaporation), causing wet regions to become wetter and dry regions become drier (Allen and Ingram 2002), as well as increasing the frequency and intensity of extreme weather events (Held and Soden 2006). In general, this raises concern for freshwater ecosystems 
46 which are highly sensitive to changes in water availability and contain many species

47

48

49

50

51

52

53

54

55

56

57

58

59

60

61

62

63

64

65

66

67

68

69

70

71

72

73

74

75

76

77

78

79

80

81

82

83

84

85

86

87

88

89

90

91

with limited dispersal capabilities (Woodward et al. 2010).

Stream ecosystems are shaped by flow regimes which regulate the physical extent of aquatic habitats, water quality, sourcing and exchange rates of material, and habitat connectivity (Rolls et al. 2012). Aridification increases the prevalence of droughts and flash floods which disturb local communities by imposing intolerable conditions or physically displacing individuals. Lengthening dry periods cause changes in macroinvertebrate communities where drought sensitive taxa (Ephemeroptera, Plecoptera, and Trichoptera) are replaced by drought tolerant species (Storey 2016). In contrast, humid precipitation regimes have low interannual variability and frequent bank flooding that promotes hydrological connectivity and resource exchange between aquatic and terrestrial systems. Fish communities become increasingly diverse with precipitation and temperature along continental climate gradients (Griffiths et al. 2014). The expansion of semi-arid regions (Huang et al. 2015) warrants an improved understanding of the mechanistic links between precipitation, flow regime, and aquatic biota to manage for the increasing societal demands for freshwater resources.

Hierarchical community assembly models can help us organize our hypotheses regarding impacts of climate change on stream communities (Poff 1997). Assuming organisms can disperse to a habitat, they must be able to survive in the local environment (abiotic filters) and successfully reproduce in the presence of other organisms exerting pressures (biotic interactions) such as competition and predation (Patrick and Swan 2011). Species have physiological tolerances (temperature, toxin concentrations, and salinity, etc.) which limit their distribution across environmental gradients (Whittaker et al. 2001). If climate change alters those gradients, we can expect concordant changes in species distributions. However, understanding how the environment affects biotic interactions is more challenging due to the complex sets of interactions that govern these processes (Seabra et al. 2015).

Observational surveys of existing communities spatially distributed along environmental gradients can be used in a space-for-time substitution to infer how communities will change through time as environmental conditions shift. The approach allows for links to be drawn between climate drivers, local environmental conditions, and organism abundances. Species co-occurrence patterns along environmental gradients can also shed light on possible shifts in biotic interactions (D'Amen et al. 2018). However, the space-for-time approach assumes that observed ecological differences along the spatial gradient are the sole product of corresponding changes in climate. This assumption may be unfair given that biogeographical studies have revealed that dispersal limitation, habitat heterogeneity, and local evolution can also contribute to current spatial patterns in community composition (Jacob et al. 2015). These studies are typically large in scale, covering vast distances (thousands of $\mathrm{km}$ ) to capture climate gradients. These large scales make the precise mechanisms for observed biological changes difficult to ascertain due to covarying environmental variables (e.g., elevation, geology, human impacts). Thus, while current literature demonstrates that biome shifts occur across temperature and latitudinal gradients (De Frenne et al. 2013), the value of these observational studies for forecasting community responses to climate change is hindered by the many confounding variables. The power of using the space-for-time approach to delineate the intricacies of hydrologic cycle-ecosystem relationships is

Peer) reviewing PDF | (2020:09:53133:3:0:NEW 12 Aug 2021) 
92 enhanced in study systems with limited confounding environmental variables

93 (temperature, elevation, distance, and underlying geology).

The Texas Coastal Prairie (TCP) within the Western Gulf coastal grasslands is an ideal system for evaluating the effect of hydrologic climate change on ecological communities. It is located within the Western Gulf coastal grasslands which are a subtropical ecotone that spans Louisiana, Texas, and northern Mexico's coastal areas. The system encompasses the sharpest non-montane precipitation gradient in the continental United States. The climate becomes more arid as you move west, with gradual change for much of the coast and a region of rapid change located in southern Texas. In this region the annual rainfall changes from $55 \mathrm{~cm} \cdot y \mathrm{r}-1$ (semi-arid) to 135 $\mathrm{cm} \bullet \mathrm{yr}-1$ (sub-humid) over a $300 \mathrm{~km}$ gradient, but there are minimal changes in elevation, air temperature, underlying geology, and human land use. The region is characterized by gently rolling landscapes (slopes $<5 \%$ ), afisol soils, streams with forested riparian zones, and a widespread conversion of grasslands to the agricultural production of cattle, cotton, corn, and soy products (Chapman 2018). As conditions become wetter, there is an observable ecological shift from mesquite groves in the semi-arid West to live oak and pecan forests towards the East. The TCP is an ideal study region for isolating precipitation influences on natural ecosystem processes because of the minimal impact of covarying predictors that typify climate gradient research.

Despite the intrinsic value of this region as a candidate for climate gradient research, there is limited prior biological sampling by governmental agencies of running waters in the TCP. To address this need, we conducted the first dedicated survey of streams across the climate gradient. We applied rapid bioassessment protocols to 10 USGS-gauged (U.S. Geological Survey), wadeable streams for characterization of fish, benthic macroinvertebrates, and quantification of environmental variables. Our objectives were to: 1) Isolate and clarify the effects of annual precipitation on patterns in the diversity and composition of fish and macroinvertebrates communities, and 2) Specify the hydrologic and water quality predictors that mediate the effects of precipitation on community assembly. We expected that annual precipitation would be positively correlated with community diversity because humid precipitation regimes are expected to create more stable environmental conditions by creating predictable flow regimes which promote the development of greater biodiversity (Boulton et al. 1992; Bunn and Arthington 2002). We further expected that evapotranspiration by riparian vegetation would increase solute concentrations in semi-arid streams, particularly during base flows (Tabacchi et al. 2000; Lupon et al. 2016), creating environmental filters that limit recruitment of sensitive fish and macroinvertebrates (hereafter referred to as invertebrates).

\section{Methods}

Study Region: The Texas Coastal Prairie contains grassland prairie with forested areas occurring primarily along riverine systems. During March and April of 2017, we sampled ten, wadeable, perennial streams which span 12 counties from Kleberg County to Montgomery in South-Central Texas, USA (Fig. 1). Each study site was located within 100 meters of a USGS stream gauge which continuously monitor streamflow and climate data year-round. Study sites were chosen to maximize differences in 
138 precipitation with minimal changes in underlying geology and elevation. The annual

139 precipitation ranges from $61-121 \mathrm{~cm}$ within the study region which spans a linear

140 distance from end to end of $378 \mathrm{~km}$ (Falcone 2011). The surface geology is

141 characterized by fine clays, quaternary and sedimentary sand. The streams have similar

142 elevations (14-62 m), substrates (quaternary), and average air temperatures (19.8-

$14322.1^{\circ} \mathrm{C}$ ) (Falcone 2011 ). Sampling was conducted by students and faculty at Texas A\&M

144 (Corpus Christi) under permit SPR-0716-170, granted by Texas Parks and Wildlife

145 Department.

146

Biological Sampling: Fish communities were sampled using a Smith-Root LR-24 Backpack in a single pass survey (Lamberti 2017). Each reach length was 25 times the average stream width, in accordance with EPA rapid bioassessment protocols (US EPA 2019). Low variability in stream withs $(4.9 \pm .6 \mathrm{~m})$ resulted in comparable catch effort across sites, so fish abundances were reported in terms of catch per sample event. Fish species were field identified to species using a field guide (Thomas et al. 2007) and photographed. Several specimens of each species were euthanized using tricaine mesylate (MS-222) and stored in $>70 \%$ denatured ethanol as voucher specimens for lab confirmation of species identification. Fish Voucher specimens were identified using the Texas Academy of Science dichotomous key (Hubbs, Edwards, and Garrett 2008) and cross referenced with field identifications. Vertebrate sampling was permitted by the Institutional Animal Care and Use Committee, Texas A\&M University Corpus Christi (AUP\# 05-17).

Invertebrates were collected using a $0.305 \mathrm{~m}$ wide D-frame net equipped with $500-\mu \mathrm{m}$ mesh. Twenty $0.093 \mathrm{~m}^{2}$ samples were collected via a combination of kick and sweep (15 s duration) sampling from a representative distribution of best available habitat (riffles, large woody debris, overhanging vegetation) (Southerland et al. 2007). Samples were pooled in a 500- $\mu \mathrm{m}$ sieve bucket where larger sticks and leaves were rinsed and removed. The captured invertebrates and remaining debris were preserved in $95 \% \mathrm{EtOH}$ for transport to the lab. In the lab, samples were spread across a gridded sampling tray and randomly selected grid cells were picked to completion until the total count was $>300$ individuals (USEPA 2015). Samples containing less than 300 individuals were picked to completion. Invertebrates were identified to lowest taxonomic resolution (typically genus) using taxonomic keys cross referenced with species observations recorded by the TCEQ's (Texas Commission on Environmental Quality) Surface Water Quality Monitoring Program (Wiggins 2015; Cummins and Merritt 1996). The sum of individuals in each taxon were multiplied by the fraction of unpicked sample and reported as abundance of individuals per square meter.

Environmental Data: For each stream, we averaged values for each of the following habitat measurements that were taken at 4 cross-sections spaced $25 \mathrm{~m}$ apart. A Rosgen Index value was calculated by dividing the bank-full width by the maximum depth (Rosgen 2001). Bank height was recorded as vertical difference between water level and the height of the first bench. We estimated sediment grain size within each crosssection using Wentworth size categories to calculate a median grain-size (d50) (Wentworth 1922). Oxygen, temperature ( $\left.\mathrm{T}_{\text {water }}\right)$, conductivity, turbidity, and $\mathrm{pH}$ were measured at each point using a YSI ProDSS multiparameter probe. Two $60 \mathrm{~mL}$ water 
184 samples were collected and filtered through a pre-combusted $\left(500^{\circ} \mathrm{C}\right.$ for 4 hours) glass 185 fiber filter (Whatman GF/F) into acid washed amber bottles, transferred to the lab in a 186 cooler on ice, and stored frozen $\left(-20^{\circ} \mathrm{C}\right)$ until analysis for nutrients $\left(\mathrm{NH}_{4}{ }^{+}, \mathrm{NO}_{3}{ }^{-}\right.$, and $\mathrm{PO}_{4}{ }^{-}$

187 ). Water samples were run using colorimetric methods on a latchet autoanalyzer by the Oklahoma University Soil Water and Forage Laboratory.

In addition to the habitat metrics measured in the field, we gathered climate and watershed data, from the US Geologic Surveyors Geospatial Attributes of Gages for Evaluating Streamflow, version II dataset (Falcone 2011). A twenty-year continuous daily flow record was downloaded for each site (except Tranquitas Creek which only had 4 years of available data) from the USGS Water Services (https://waterservices.usgs.gov).

Analyses: Due to a small number of sample sites and replicates, the statistical analyses relating environmental drivers to organismal responses were restricted to six a priori environmental predictors. Annual precipitation was evaluated to identify gradient effects. Channel shape is a product of flow regime, slope, substrate, and bank stability and was summarized by the Rosgen index. We included conductivity and $\mathrm{NH}_{4}{ }^{+}$to evaluate water quality. Since the selected streams were deliberately chosen to be wadeable at base flow, we calculated two flow metrics to approximate the typical flow regime of each site in the context of seasonal droughts and floods, as well as overall variation in flow: Flash Index (cumulative changes in day to day daily flow / cumulative flow) and the Low-Flow Pulse Percent (LFPP = times where daily discharge drops below the $25^{\text {th }}$ percentile) (Olden and Poff 2003; Patrick and Yuan 2017).

We used linear regression and Pearson correlation coefficients to identify potential confounding relationships between precipitation and each environmental predictor. We then, used singular value decomposition of the centered and scaled data matrix in a principal component analysis with all six environmental predictors. The environmental PCA and associated exploratory results are described in the supplemental data.

For each community (fish and invertebrate) we estimated coverage and Hill diversity metrics (Roswell et al. 2021). We used coverage-based estimates of species richness, Shannon entropy and Gini-simpson index (Chao et al. 2014). While richness and Gini-Simpson index values are reported in supplemental materials, further analyses and discussion regarding diversity utilize the Shannon Entropy because it is not overly sensitive to either rare or common species. We used univariate regression to evaluate community diversity relationships with the precipitation gradient and each environmental predictor. We also performed exhaustive multiple regression with an additive global model utilizing all six environmental predictors and ranked them using Aikake's information criterion corrected for small sample sizes $\left(\mathrm{AIC}_{\mathrm{c}}\right)$. All the results were compared to the best overall model by calculating the difference in $\mathrm{AlC}_{\mathrm{c}}$ values $\left(\triangle \mathrm{AlC}_{\mathrm{c}}\right)$. Models with $\triangle \mathrm{AIC}_{\mathrm{c}}<2$ were considered to have substantial support (Burnham and Anderson 2002). Diversity Hill metrics were calculated using the iNEXT package (Hsieh et al. 2020) in R (R Core Team 2018).

To discern compositional shifts in fish and invertebrates across the precipitation gradient, we used Redundancy Analysis (RDA) on Hellinger-transformed community data, constrained to the six environmental variables in Table 1 (Legendre and Gallagher 
230

231

232

233

234

235

236

237

238

239

240

241

242

243

244

245

246

247

248

249

250

251

252

253

254

255

256

257

258

259

260

261

262

263

264

265

266

267

268

269

270

271

272

273

274

275

2001; Legendre and Legendre 2012). We then fit vectors to the species and environmental variables where the direction of each arrow is determined by the average directional cosines from the origin to site values within the ordination. Significant vectors had an associated $p$-value $<0.05$. Ordination and vectors were calculated using the 'rda' and 'envfit' functions respectively in the vegan package in $\mathrm{R}$ (J. Oksanen et al. 2019, Bellier et al. 2012). Statistics and analytical R scripts for analyses described above are reported in the supplemental data.

\section{Results}

Fish Community: Eighteen fish species were identified. Proceeding from semi-arid to sub-humid sites, Shannon entropy increased from 1.6 to 6.1 and richness increased from 2 to 9 species (Fig. 2). Univariate regressions indicate that Shannon diversity is positively correlated with precipitation and negatively correlated with conductivity (Table 1). Multiple regression indicates that precipitation alone is the strongest predictor of Shannon diversity.

Communities along the precipitation gradient are stratified in ordination space with significant vector loading on $\mathrm{NH}_{4}{ }^{+}$(Fig. 3). The position of species and sites indicate that compositions shift from small, elongate live-bearer taxa (Poecilia latipinna, and Gambusia affinis) in the most arid sites to deep-bodied, nesting centrarchids (Lepomis megalotis and Lepomis macrochirus) in the more humid sites. Some mesic and humid stream communities are distinguished by the presence of Cyprinella lutrensis, a small, invasive habitat-generalist. Species found in small numbers or at singular sites fail to produce significant vectors in the RDA. Unique species found in sites on the humid side of the climate gradient include hogchoker (Trinectes maculatus), black bullhead catfish (Ameirus melas), and blacktail shiner (Cyprinella venusta).

Invertebrate Community: In total, 94 invertebrate genera were identified. Invertebrate richness ranged 7-29 genera with the highest values occurring at three sites in the middle of the precipitation gradient (Fig. 4). Regression analysis indicates that Shannon entropy does not significantly correlate with precipitation. However, multiple regression indicates that invertebrate diversity relates negatively with LFPP (Table 1).

Communities along the precipitation gradient stratify in ordination space along opposite/parallel axes of precipitation and conductivity. Arid communities are strongly correlated with gastropods including a non-native burrowing snail (Melanoides tuberculata). Mesic invertebrate communities are strongly correlated with crawling beetles (Hydraena) and swimming beetles (Peltodytes). The most humid communties correlate with several Ephemeroptera (Caenis and Plauditus), Crustacea (Palaemonetes), Amphipoda (Hyalella), and Trichoptera (Cheumatopsyche).

\section{Discussion}

Our goal was to quantify patterns in the diversity and composition of stream communities along an extreme precipitation gradient to better understand how streams might respond to future changes in mean annual rainfall. We identified compositional shifts in both fish and invertebrate communities along the precipitation gradient. We also observed a positive relationship between fish diversity and mean annual rainfall, matching expectations, whereas invertebrate diversity did not exhibit the expected 
276 relationships with rainfall. Changes in water solute concentrations and flow regime

277

278

279

280

281

282

283

284

285

286

287

288

289

290

291

292

293

294

295

296

297

298

299

300

301

302

303

304

305

306

307

308

309

310

311

312

313

314

315

316

317

318

319

320

321 appear to be additional important drivers of community responses.

The fish communities displayed increasing diversity moving from the drier to wetter sides of the survey region. Fish diversity increased with precipitation but was negatively related to conductivity, $\mathrm{NH}_{4}{ }^{+}$, and canopy coverage. Elevated conductivity and $\mathrm{NH}_{4}{ }^{+}$in semi-arid streams exhibited levels similar to urbanized streams (Hatt et al. 2004), creating stressful osmotic and toxic conditions for fish (J. M. Redding and Schreck 1983; Lock and Wendelaar Bonga 1991). Elevated $\mathrm{NH}_{4}{ }^{+}$has been shown to be directly toxic to many fish (Randall and Tsui 2002) and has also fueled cytotoxic algal growth (Fetscher et al. 2015). Elevated solute concentrations were likely driven by evaporation, the watershed area/discharge ratio, and the greater influence of wastewater effluent on low discharge streams that typify semi-arid streams (Williams 1999; Dehedin et al. 2013). We interpreted these patterns to mean that as conditions become drier, water quality imposes abiotic filters on fish assembly which reduce overall community diversity and selects for taxa with specialized adaptations for the harsh conditions. The negative relationship between fish diversity and canopy coverage was attributed to incomplete leaf-emergence in deciduous canopies prior to May.

Communities in semi-arid streams were composed of small, live-bearing, omnivores able to tolerate high salinities including Sailfin Molly (Poecilia latipinna, 95 psu) and Western Mosquitofish (Gambusia affinis, 58.5 psu) (Page and Burr, B.M. 1991). The strongest compositional shift observed were increases in the abundance of centrarchids (sunfish) with increases in annual rainfall. Centrarchid species have 3-7 year lifespans, breed annually, build nests, and are omnivores (Cooke and Philipp 2009). Additional increases in diversity towards the wetter side of the climate gradient included the addition of black bullhead catfish (a demersal, nesting omnivore), and several shiner species (small broadcast spawning minnows). These organisms require conditions that are stable across years as well as suitable substrate for rearing young, suggesting that conditions in semi-arid sites were excluding these taxa through environmental filtering. Additionally, some of the sub-humid and mesic sites also had seasonally migrating taxa including Rio Grande Cichlid (Hericthys cyanogutattus), Hogchoker (Trinectes maculatus), and American Eel (Anguilla rostrate) (Rehage et al. 2016; Koski 1978; Wenner 1978). These were absent from semi-arid sites. Given the similar proximity to nearby reservoirs and estuaries, migratory taxa may have been excluded from streams with habitat fragmentation, approximated here by low flow pulse $\%$, that typify semi-arid streams (De Jong et al. 2015).

Contrary to expectations, Red shiners (Cyprinella lutrensis) were absent from semi-arid sites and were only present in four mesic and sub-humid sites. In ordination space, two sites with the highest abundances of red shiner (Aransas and Placedo) separated perpendicularly from the rainfall-gradient effects and coextended with stream morphology and hydrologic flashiness indices. High abundances of red shiner were associated with shallow riffle habitats with gravel substrates which occurred at three sites throughout the gradient. This was peculiar since red shiner are considered to be a habitat generalist and rugged invasive throughout the United States (Marsh-Matthews and Matthews 2000; Matthews and Marsh-Matthews 2007). We suspected their apparent habitat preference was driven by competition and predation by centrarchids in nearby pool and run habitats. Although red shiners tolerate high temperatures and low

Peer) reviewing PDF | (2020:09:53133:3:0:NEW 12 Aug 2021) 
322 oxygen, conductivity was likely excluding red shiner (salinity tolerance $<10 \mathrm{psu}$ ) from

323 the arid sites (Matthews and Hill 1977). In this light, we considered hydrologic flashiness

324 a spurious influence on red shiner distributions beyond its capacity to influence channel

325 geomorphology.

326 LFPP approximated drought prevalence and was the sole significant predictor of

327 invertebrate community diversity. In addition to LFPP, the top-ranked multiple

328 regression models also implicated $\mathrm{NH}_{4}{ }^{+}$was an effective predictor of invertebrate

329 diversity. These results corroborate expectations for the ramping disturbance conditions

330 typical of droughts in which water availability and quality diminish over time. Compared

331 to fish, invertebrates have restricted in-stream mobility and traditionally seek refuge in

332 the hyporheic zone, interstitial spaces, and in some cases utilize desiccation-resistant

333 life-stages (Boulton et al. 1992; Boulton 2003). Here, Semi-arid community

334 compositions included a higher proportion of gastropods which are well adapted to the

335

336

337

338

339

340

341

342

343

344

345

346

347

348

349

350

351

352

353

354

355

356

357

358

359

360

361

362

363

364

365

366

367 stresses that characterize increased LFPP. For example, M. tuberculata were the most abundant primary consumers in the semi-arid streams and can resist the osmotic stress imposed by drought conditions with a broad range of salinity tolerance (0-23 PSU). This species is also well-adapted to survive and reproduce throughout periodic dewatering due to its rapid maturation (21-62 days), asexual reproduction, and internal offspring gestation (Farani et al. 2015).

Despite relating with LFPP, invertebrate diversity did not correlate linearly with precipitation. Instead, invertebrate diversity peaked in the middle of the rainfall gradient. The lack of a linear correlation between invertebrate diversity and precipitation may have been caused by the inherently larger species pool for invertebrates which included more taxa with biological adaptations to drought compared to fish (Eriksson 1993). The peak likely represented the transition zone where taxa common on each side of the gradient were able to co-occur. Alternatively, the driest site (Tranquitas Creek) displayed uncharacteristically low diversity compared to other semi-arid sites and may constitute an outlier. When removed, invertebrate diversity correlated negatively with precipitation $\left(R^{2}=0.43, p\right.$-value $\left.=0.06\right)$. Regardless, the relation between precipitation and invertebrate diversity remains unclear.

Invertebrate community compositional shifts with rising precipitation invite continued assessment on the following speculative premises within the region: 1) The observed shift in primary consumers from short-lived, euryhaline dipterans and gastropods to ephemeropterans and trichopterans, environmentally sensitive species with longer lifespans, pointed towards improved water quality conditions and hydrologic stability (Rosenberg and Resh 1993; Jackson and Sweeney 1995). Taken further, this pattern alludes towards the evolutionary trade-off between aridity tolerance and competitive specialization (Fréjaville et al. 2018). 2) The increased prevalence of shredder-crustaceans (amphipods and crayfish) at wetter sites pointed towards a possible shift in available basal resources; precipitation-mediated shifts in riparian vegetation from evergreen, xeric mesquite trees to deciduous hardwoods could bring about increased allochthonous inputs to support more shredder taxa (Giling, Reich, and Thompson 2009). 3) The decreased abundance of odonate and hempiteran predators may have been due to competition with and predation by insectivorous centrarchids (Dahl and Greenberg 1998). In this way, top-down trophic interactions at sub-humid sites could have restricted invertebrate communities to species with anti-predator

Peer) reviewing PDF | (2020:09:53133:3:0:NEW 12 Aug 2021) 
368 adaptations including small size, passive foraging strategies, camouflage, and armoring

369 (Straile and Halbich 2000).

370

371

372

373

374

375

376

377

378

379

380

381

382

383

384

385

386

387

388

389

390

391

392

393

394

395

396

397

398

399

400

401

402

403

404

405

406

407

408

409

While this survey only consisted of 10 streams, it is the first published rapid bioassessment of systems along the rainfall gradient on the Texas Coastal Prairie. The results largely conform to a priori hypotheses indicating that the region represents a promising study region for climate research. In addition to its capacity for a space for time substitution, the TCP is poised to provide real-time data on the effects of climate change on ecosystems. Future research in this region would benefit from higher frequency sampling over a longer time period and quantification of invertebrate and fish functional traits. An in-depth time series study would allow for evaluation of how these communities change across seasons, how they respond to periodic droughts and floods, and how stable the communities are through time. More detailed quantification of the fish communities through depletion surveys and invertebrate communities via biomass cores would allow for greater characterization of the relative abundance of different taxa through time, and these could be linked to functional traits to explore the mechanisms behind some of the patterns that we observed here. A continuation of this sampling program with thorough methods will augment the analytical power, precision, and depth of this natural experiment.

Despite this study's limitations, our results highlight the breadth and far-reaching ecological consequences associated with small changes in precipitation. They warn that regions expected to become more arid, like Central and Western Texas (Jiang and Yang 2012), could expect a loss of competitive taxa with low environmental tolerances as observed here with centrarchids, ephemeropterans, and trichopterans. And that in their absence, rugged and euryhaline taxa (like livebearers, burrowing gastropods and predatory invertebrates) flourish. Furthermore, this study warrants investigation to clarify the causal relationships between the ecological constraints imposed by aridity and these observed community shifts.

\section{Acknowledgements}

Jennifer Whitt and lan Whitt for their contributions in the field and laboratory. This work was supported by National Science Foundation grant DEB-1761677, an Early Career Gulf Research Fellowship awarded to C. Patrick, and the Texas Comprehensive Research Fund.

\section{References:}

Allen MR, and Ingram WJ. 2002. "Constraints on Future Changes in Climate and the Hydrologic Cycle." Nature 419: 228-232. https://doi.org/10.1038/nature01092.

Baker DB, Richards RP, Loftus TT, and Kramer JW. 2004. "A New Flashiness Index: Characteristics and Applications to Midwestern Rivers and Streams1." Journal of the American Water Resources Association 40 (2): 503-22.

Bellier ED, Borcard FG, Legendre P. 2012. Numerical Ecology with R. JABES 17, 308309. https://doi.org/10.1007/s13253-012-0094-x 
410 Boulton AJ. 2003. "Parallels and Contrasts in the Effects of Drought on Stream

411 Macroinvertebrate Assemblages." Freshwater Biology 48 (7): 1173-85.

412 https://doi.org/10.1046/j.1365-2427.2003.01084.x.

413 Boulton AJ., Peterson CG, Grimm NB, and Fisher SG. 1992. "Stability of an Aquatic

414 Macroinvertebrate Community in a Multiyear Hydrologic Disturbance Regime." Ecology

41573 (6): 2192-2207. https://doi.org/10.2307/1941467.

416 Burnham KP, and Anderson DR. 2002. Model Selection and Multimodel Inference: A

417 Practical Information-Theoretic Approach. 2nd ed. New York: Springer-Verlag.

418 https://doi.org/10.1007/b97636.

419 Chao A, Gotelli NJ, Hsieh TC, Sande EL, Ma KH, Colwell RK, Ellison AM (2014).

420 "Rarefaction and extrapolation with Hill numbers: a framework for sampling and

421 estimation in species diversity studies." Ecological Monographs, 84, 45-67.

422 Chapman BE. 2018. The Natural History of Texas. College Station: Texas A\&M

423 University Press. https://www.tamupress.com/9781623495725/the-natural-history-of-

424 texas.

425 Connor S, Nelson PN, Armour JD, and Henault C. 2013. "Hydrology of a Forested

426 Riparian Zone in an Agricultural Landscape of the Humid Tropics." Agriculture

427 Ecosystems \& Environment 180 (November): 111-22.

428 https://doi.org/10.1016/j.agee.2011.12.006.

429 Cooke S, and Philipp D. 2009. Centrarchid Fishes: Diversity, Biology, and Conservation.

430 https://doi.org/10.1002/9781444316032.

431 Cummins K, and Merritt R. 1996. "An Introduction to The Aquatic Insects of North

432 America." The Journal of Animal Ecology 50 (September).

433 https://doi.org/10.2307/1467288.

434 Dahl J, and Greenberg LA. 1998. "Effects of Fish Predation and Habitat Type on Stream 435 Benthic Communities." Hydrobiologia 361: 67-76.

436 D'Amen, M, Mod HK, Gotelli NJ, and Guisan A. 2018. "Disentangling Biotic Interactions, 437 Environmental Filters, and Dispersal Limitation as Drivers of Species Co-Occurrence."

438 Ecography 41 (8): 1233-44. https://doi.org/10.1111/ecog.03148.

439 De Frenne, P, Graae BJ, Rodriguez-Sanchez F, Kolb A, Chabrerie O, Decocq G, De 440 Kort H, De Schrivjer A, Diekmann M, Eriksson O, Gruwez R, Hermy M, Lenoir J, Plue J, 441 Coomes DA, Verheyen K. 2013. "Latitudinal Gradients as Natural Laboratories to Infer 442 Species' Responses to Temperature." Journal of Ecology 101 (3): 784-95.

443 https://doi.org/10.1111/1365-2745.12074.

444 De Jong GD, Canton SP, Lynch JS, and Murphy M. 2015. "Aquatic Invertebrate and 445 Vertebrate Communities of Ephemeral Stream Ecosystems in the Arid Southwestern 446 United States." The Southwestern Naturalist 60 (4): 349-59. 
447 Dehedin A, Maazouzi C, Puijalon S, Marmonier P, and Piscart C. 2013. "The Combined 448 Effects of Water Level Reduction and an Increase in Ammonia Concentration on 449 Organic Matter Processing by Key Freshwater Shredders in Alluvial Wetlands." Global 450 Change Biology 19 (3): 763-74. https://doi.org/10.1111/gcb.12084.

451 Eriksson O. 1993. "The Species-Pool Hypothesis and Plant Community Diversity." 452 Oikos 68 (2): 371-74. https://doi.org/10.2307/3544854.

453 Elliott JM. 2008. "The Ecology of Riffle Beetles (Coleoptera: Elmidae)." Freshwater 454 Reviews 1(2), 189-203. https://doi.org/10.1608/FRJ-1.2.4

455 Falcone J. 2011. "GAGES-II: Geospatial Attributes of Gauges for Evaluating 456 Streamflow." Reston, Virginia: U.S. Geological Survey. 457 https://water.usgs.gov/GIS/metadata/usgswrd/XML/gagesIl_Sept2011.xml.

458 Farani GL., Nogueira M, Johnsson R, and Neves E. 2015. "The Salt Tolerance of the 459 Freshwater Snail Melanoides Tuberculata (Mollusca, Gastropoda), a Bioinvader 460 Gastropod" 10 (January): 212-21.

461 Fetscher AE, Howard MDA, Stancheva R, Kudela RM, Stein ED, Sutula MA, Busse LB, 462 and Sheath RG. 2015. "Wadeable Streams as Widespread Sources of Benthic

463 Cyanotoxins in California, USA." Harmful Algae 49 (November): 105-16.

464 https://doi.org/10.1016/j.hal.2015.09.002.

465 Fréjaville T, Vilà-Cabrera A, Curt T, and Carcaillet C. 2018. "Aridity and Competition 466 Drive Fire Resistance Trait Covariation in Mountain Trees." Ecosphere 9 (12): e02493. 467 https://doi.org/10.1002/ecs2.2493.

468 Giling D, Reich P, and Thompson RM. 2009. "Loss of Riparian Vegetation Alters the 469 Ecosystem Role of a Freshwater Crayfish (Cherax Destructor) in an Australian 470 Intermittent Lowland Stream." Journal of the North American Benthological Society 28 471 (3): 626-37. https://doi.org/10.1899/09-015.1.

472 Griffiths D, McGonigle C, and Quinn R. 2014. "Climate and Species Richness Patterns 473 of Freshwater Fish in North America and Europe." Journal of Biogeography 41 (3): 452 474 63. https://doi.org/10.1111/jbi.12216.

475 Hatt BE, Fletcher TD, Walsh CJ, and Taylor SL. 2004. "The Influence of Urban Density 476 and Drainage Infrastructure on the Concentrations and Loads of Pollutants in Small 477 Streams." Environmental Management 34 (1): 112-24. https://doi.org/10.1007/s00267478 004-0221-8.

479 Held IM, and Soden BJ. 2006. "Robust Responses of the Hydrological Cycle to Global 480 Warming." Journal of Climate 19 (21): 5686-99. https://doi.org/10.1175/JCLI3990.1.

481 Hsieh TC, Ma KH, Chao A (2020). iNEXT: Interpolation and Extrapolation for Species 482 Diversity. $R$ package version 2.0.20, 483 http://chao.stat.nthu.edu.tw/wordpress/software_download/. 
484 "Https://Waterservices.Usgs.Gov/." n.d. USGS Water Services. Accessed June 1, 2020. 485 https://waterservices.usgs.gov/.

486 Huang J, Mingxia J, Yongkun X, Shanshan W, Yongli H, and Jinjiang R. 2016. "Global 487 Semi-Arid Climate Change Over Last 60 Years." Climate Dynamics 46 (3-4): 1131-50. 488 https://doi.org/10.1007/s00382-015-2636-8.

489 Hubbs C, Edwards RJ, and Garrett GP. 2008. "An Annotated Checklist of the

490 Freshwater Fishes of Texas, with Keys to Identification of Species, 2nd Edition," July. 491 https://repositories.lib.utexas.edu/handle/2152/6290.

492 Hurlbert SH. 1971. "The Nonconcept of Species Diversity: A Critique and Alternative 493 Parameters." Ecology 52 (4): 577-86. https://doi.org/10.2307/1934145.

494 Jackson JK., and Sweeney BW. 1995. "Egg and Larval Development Times for 35 495 Species of Tropical Stream Insects from Costa-Rica." Journal of the North American 496 Benthological Society 14 (1): 115-30. https://doi.org/10.2307/1467728.

497 Jacob S, Bestion E, Legrand D, Clobert C, and Cote J. 2015. "Habitat Matching and 498 Spatial Heterogeneity of Phenotypes: Implications for Metapopulation and 499 Metacommunity Functioning." Evolutionary Ecology 29 (6): 851-71.

500 https://doi.org/10.1007/s10682-015-9776-5.

501 Jiang X, and Yang ZI. 2012. "Projected Changes of Temperature and Precipitation in 502 Texas from Downscaled Global Climate Models." Climate Research 53 (3): 229-44. 503 https://doi.org/10.3354/cr01093.

504 Jones I, Growns I, Arnold A, McCall S, and Bowes M. 2015. "The Effects of Increased 505 Flow and Fine Sediment on Hyporheic Invertebrates and Nutrients in Stream

506 Mesocosms." Freshwater Biology 60 (4): 813-26. https://doi.org/10.1111/fwb.12536.

507 Koski RT. 1978. "Age, Growth, and Maturity of Hogchoker, Trinectes-Maculatus, in 508 Hudson River, New-York." Transactions of the American Fisheries Society 107 (3): 509 449-53. https://doi.org/10.1577/1548-8659(1978)107<449:AGAMOT>2.0.CO;2.

510 Lamberti H. 2017. Methods in Stream Ecology | ScienceDirect. 3rd Edition. Elsevier. 511 https://www.sciencedirect.com/book/9780128130476/methods-in-stream-ecology.

512 Legendre P, and Gallagher ED. 2001. "Ecologically Meaningful Transformations for

513 Ordination of Species Data." Oecologia 129 (2): 271-80.

514 https://doi.org/10.1007/s004420100716.

515 Legendre P, and Legendre L. 2012. Numerical Ecology. 3rd edition. Elsevier.

516 Lock RAC., and Wendelaar Bonga SE. 1991. "Toxicants and Osmoregulation in Fish." 517 Netherlands Journal of Zoology 42 (2-3): 478-93.

518 https://doi.org/10.1163/156854291X00469. 
519 Lupon A, Bernal S, Poblador S, Marti E, and Sabater F. 2016. "The Influence of

520 Riparian Evapotranspiration on Stream Hydrology and Nitrogen Retention in a

521 Subhumid Mediterranean Catchment." Hydrology and Earth System Sciences 20 (9):

522 3831-42. https://doi.org/10.5194/hess-20-3831-2016.

523 Marsh-Matthews E, and Matthews WJ. 2000. "Spatial Variation in Relative Abundance

524 of a Widespread, Numerically Dominant Fish Species and Its Effect on Fish

525 Assemblage Structure." Oecologia 125 (2): 283-92.

$526 \mathrm{https}: / /$ doi.org/10.1007/s004420000452.

527 Matthews WJ, and Hill LG. 1977. "Tolerance of the Red Shiner, Notropis Lutrensis

528 (Cyprinidae) to Environmental Parameters." The Southwestern Naturalist 22 (1): 89-98.

529 https://doi.org/10.2307/3670466.

530 Matthews WJ., and Marsh-Matthews E. 2007. "Extirpation of Red Shiner in Direct

531 Tributaries of Lake Texoma (Oklahoma-Texas): A Cautionary Case History from a

532 Fragmented River-Reservoir System." Transactions of the American Fisheries Society

533136 (4): 1041-62. https://doi.org/10.1577/T06-059.1.

534 Miranda LE, Coppola G, and Boxrucker J. 2020. "Reservoir Fish Habitats: A

535 Perspective on Coping with Climate Change." Reviews in Fisheries Science \&

536 Aquaculture 28 (4): 478-98. https://doi.org/10.1080/23308249.2020.1767035.

537 Oksanen J, Blanchet FG, Friendly M, Kindt R, Legendre P, McGlinn D, Minchin PR,

538 O'Hara RB, Simpson GL, Solymos P, Stevens MHH, Szoecs E, Wagner H. 2019.

539 Vegan: Community Ecology Package (version 2.5-6). https://CRAN.R-

540 project.org/package=vegan.

541 Olden JD, and Poff NL. 2003. "Toward a Mechanistic Understanding and Prediction of

542 Biotic Homogenization." American Naturalist 162 (4): 442-60.

543 https://doi.org/10.1086/378212.

544 Page LM, and Burr BM. 1991. A Field Guide to Freshwater Fishes of North America

545 North of Mexico. Boston: Houghton Mifflin Company.

546 https://fishbase.in/references/FBRefSummary.php?ID=5723.

547 Patrick CJ., and Yuan LL. 2017. "Modeled Hydrologic Metrics Show Links between

548 Hydrology and the Functional Composition of Stream Assemblages." Ecological

549 Applications 27 (5): 1605-17. https://doi.org/10.1002/eap.1554.

550 Patrick CJ., and Swan CM. 2011. "Reconstructing the Assembly of a Stream-Insect

551 Metacommunity." Journal of the North American Benthological Society 30 (1): 259-72.

552 https://doi.org/10.1899/09-169.1.

553 Poff NL. 1997. "Landscape Filters and Species Traits: Towards Mechanistic

554 Understanding and Prediction in Stream Ecology." Journal of the North American

555 Benthological Society 16 (2): 391-409. https://doi.org/10.2307/1468026. 
556 R Core Team. 2018. R: A Language and Environment for Statistical Computing. Vienna, 557 Austria: R Foundation for Statistical Computing. https://www.R-project.org/.

558 Randall DJ, and Tsui TKN. 2002. "Ammonia Toxicity in Fish." Marine Pollution Bulletin, 559 45:17-23.

560 Redding JM, and Schreck CB. 1983. "Influence of Ambient Salinity on Osmoregulation 561 and Cortisol Concentration in Yearling Coho Salmon during Stress." Transactions of the 562 American Fisheries Society 112 (6): 800-807. https://doi.org/10.1577/1548-

563 8659(1983)112<800:IOASOO>2.0.CO;2.

564 Rehage JS, Blanchard JR, Boucek RE, Lorenz JJ, and Robinson M. 2016. "Knocking 565 Back Invasions: Variable Resistance and Resilience to Multiple Cold Spells in Native vs. 566 Nonnative Fishes." Ecosphere 7 (6): e01268. https://doi.org/10.1002/ecs2.1268.

567 Rolls RJ, Leigh C, and Sheldon F. 2012. "Mechanistic Effects of Low-Flow Hydrology on 568 Riverine Ecosystems: Ecological Principles and Consequences of Alteration."

569 Freshwater Science 31 (4): 1163-86. https://doi.org/10.1899/12-002.1.

570 Rosenberg DM, and Resh VH. 1993. "Introduction to Freshwater Biomonitoring and

571 Benthic Macroinvertebrates." Freshwater Biomonitoring and Benthic

572 Macroinvertebrates, Chapman/Hall, New York.

573 Rosgen, D. 2001. "A Stream Channel Stability Assessment Procedure." Proceedings of 574 7th Federal Interagency Sedimentation Conference, 11.

575 Roswell M, Dushoff J, and Winfree R. 2021. "A Conceptual Guide to Measuring Species 576 Diversity." Oikos 130 (3): 321-38. https://doi.org/10.1111/oik.07202.

577 Schade JD., Fisher SD, Grimm NB, and Seddon JA. 2001. "The Influence of a Riparian 578 Shrub on Nitrogen Cycling in a Sonoran Desert Stream." Ecology 82 (12): 3363-76.

579 Scheffer M, and Carpenter SR. 2003. "Catastrophic Regime Shifts in Ecosystems:

580 Linking Theory to Observation." Trends in Ecology \& Evolution 18 (12): 648-56.

581 https://doi.org/10.1016/j.tree.2003.09.002.

582 Seabra R, Wethey DS, Santos AM and Lima FP. 2015. "Understanding Complex

583 Biogeographic Responses to Climate Change." Scientific Reports 5 (August): 12930.

584 https://doi.org/10.1038/srep12930.

585 Southerland M, Rogers G, Kline M, Morgan R, Boward D, \& Kazyak P. 2007. Improving 586 biological indicators to better assess the condition of streams. Ecological Indicators, 587 7(4), 751-767. doi: 10.1016/j.ecolind.2006.08.005

588 Storey R. 2016. "Macroinvertebrate Community Responses to Duration, Intensity and 589 Timing of Annual Dry Events in Intermittent Forested and Pasture Streams." Aquatic 590 Sciences 78 (2): 395-414. https://doi.org/10.1007/s00027-015-0443-2. 
591 Straile D, and Halbich A. 2000. "Life History and Multiple Antipredator Defenses of an 592 Invertebrate Pelagic Predator, Bythotrephes Longimanus." Ecology 81 (1): 150-63.

593 https://doi.org/10.1890/0012-9658(2000)081[0150:LHAMAD]2.0.CO;2.

594 Tabacchi E, Lambs L, Guilloy H, Planty-Tabacchi AM, Muller E, and Décamps H. 2000.

595 "Impacts of Riparian Vegetation on Hydrological Processes." Hydrological Processes 14 596 (16-17): 2959-76. https://doi.org/10.1002/1099-1085(200011/12)14:16/17<2959::AID597 HYP129>3.0.CO;2-B.

598 Thomas C, Bonner T, Whiteside BG, and Gelwick F. 2007. "Freshwater Fishes of 599 Texas: A Field Guide." Freshwater Fishes of Texas: A Field Guide, 1-202.

600 USEPA. 2015. "Standard Operating Procedure for Benthic Invertebrate Laboratory 601 Analysis.” LG407.

602 Wenner CA. 1978. "FAO Species Identification Sheets for Fishery Purposes. Eastern 603 Central Atlantic; Fishing Areas 34, 47 (in Part)." 1978.

604 http://www.fao.org/3/ag419e/ag419e00.htm.

605 Wentworth CK. 1922. "A Scale of Grade and Class Terms for Clastic Sediments." 606 Journal of Geology 30 (5): 377-92. https://doi.org/10.1086/622910.

607 Whittaker RJ, Willis KJ, and Field R. 2001. "Scale and Species Richness: Towards a 608 General, Hierarchical Theory of Species Diversity." Journal of Biogeography 28 (4):

609 453-70. https://doi.org/10.1046/j.1365-2699.2001.00563.x.

610 Wiggins G. 2015. Larvae of the North American Caddisfly Genera (Trichoptera).

611 Toronto, Canada: University of Toronto Press, Scholarly Publishing Division.

612 https://utorontopress.com/us/larvae-of-the-north-american-caddisfly-genera-trichoptera6134.

614 Williams WD. 1999. "Salinisation: A Major Threat to Water Resources in the Arid and 615 Semi-Arid Regions of the World." Lakes \& Reservoirs: Science, Policy and Management 616 for Sustainable Use 4 (3-4): 85-91. https://doi.org/10.1046/j.1440-1770.1999.00089.x.

617 Woodward G, Perkins DM, and Brown LE. 2010. "Climate Change and Freshwater 618 Ecosystems: Impacts across Multiple Levels of Organization." Philosophical

619 Transactions: Biological Sciences 365 (1549): 2093-2106.

620 Wrona FJ, Prowse TD, Reist JD, Hobbie JE, Levesque LMJ, and Vincent WF. 2006. 621 "Climate Change Effects on Aquatic Biota, Ecosystem Structure and Function." Ambio 62235 (7): 359-69. https://doi.org/10.1579/0044-7447(2006)35[359:CCEOAB]2.0.CO;2. 


\section{Figure 1}

Map of South-Central Texas, where 10 USGS gaged Streams were sampled in the Spring of 2017.

An annual precipitation overlay indicates that the sample sites span a gradient from $61 \mathrm{~cm} / \mathrm{yr}$ in the Southwest to $134 \mathrm{~cm} / \mathrm{yr}$ in the Northeast.

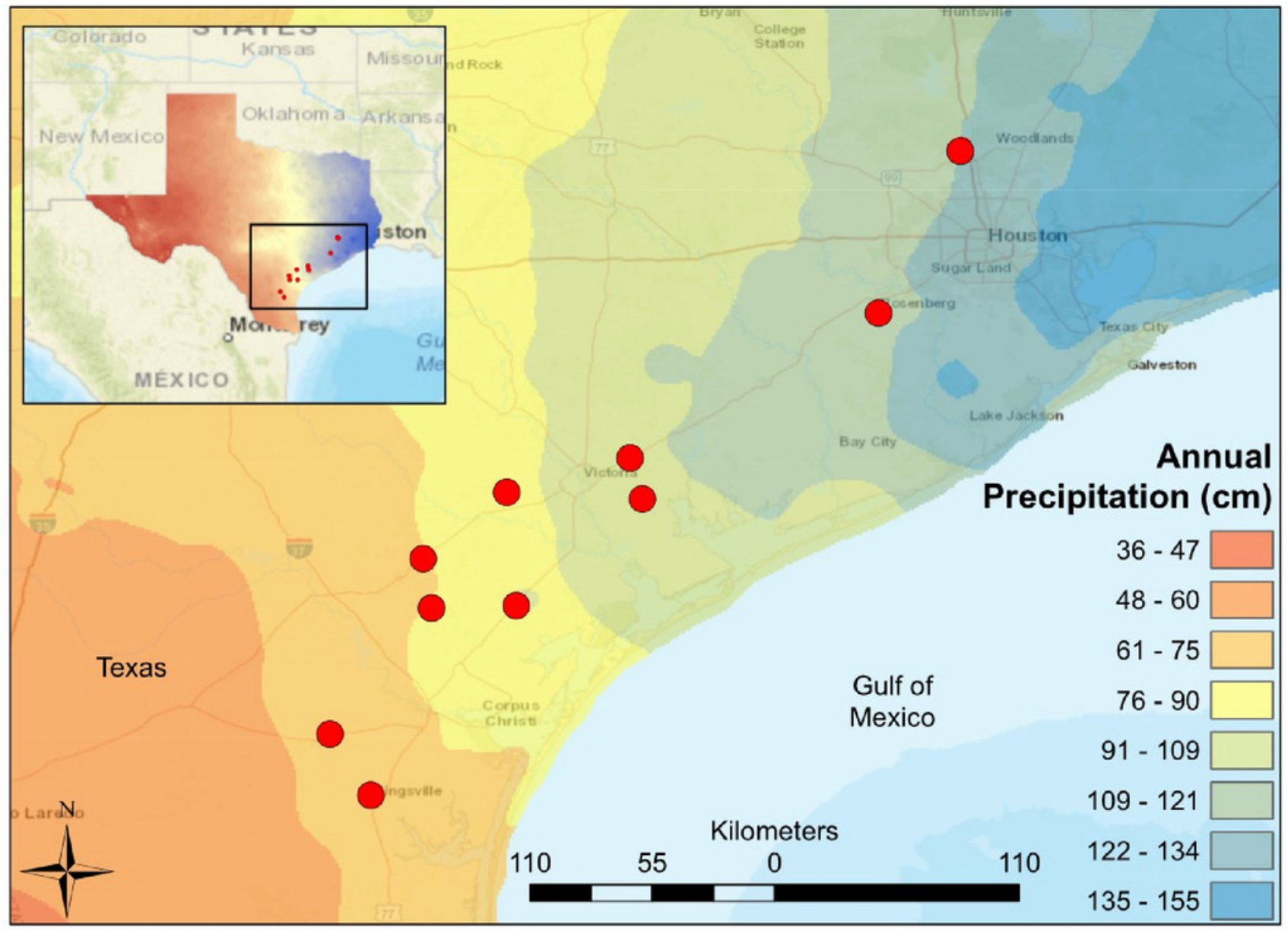


Figure 2

(A) Fish Shannon-Hill diversity plotted against annual precipitation (cm/yr) (B) Fish community ordination using Hellinger transformation and redundancy analysis. Axes labels display the proportion of the variance explained as a percentage.

Sites are represented by grey circles. Species are represented by red crosses, with species labels and reference images added to outer members. Environmental variables are shown in arrows and the significant ones are presented in red.
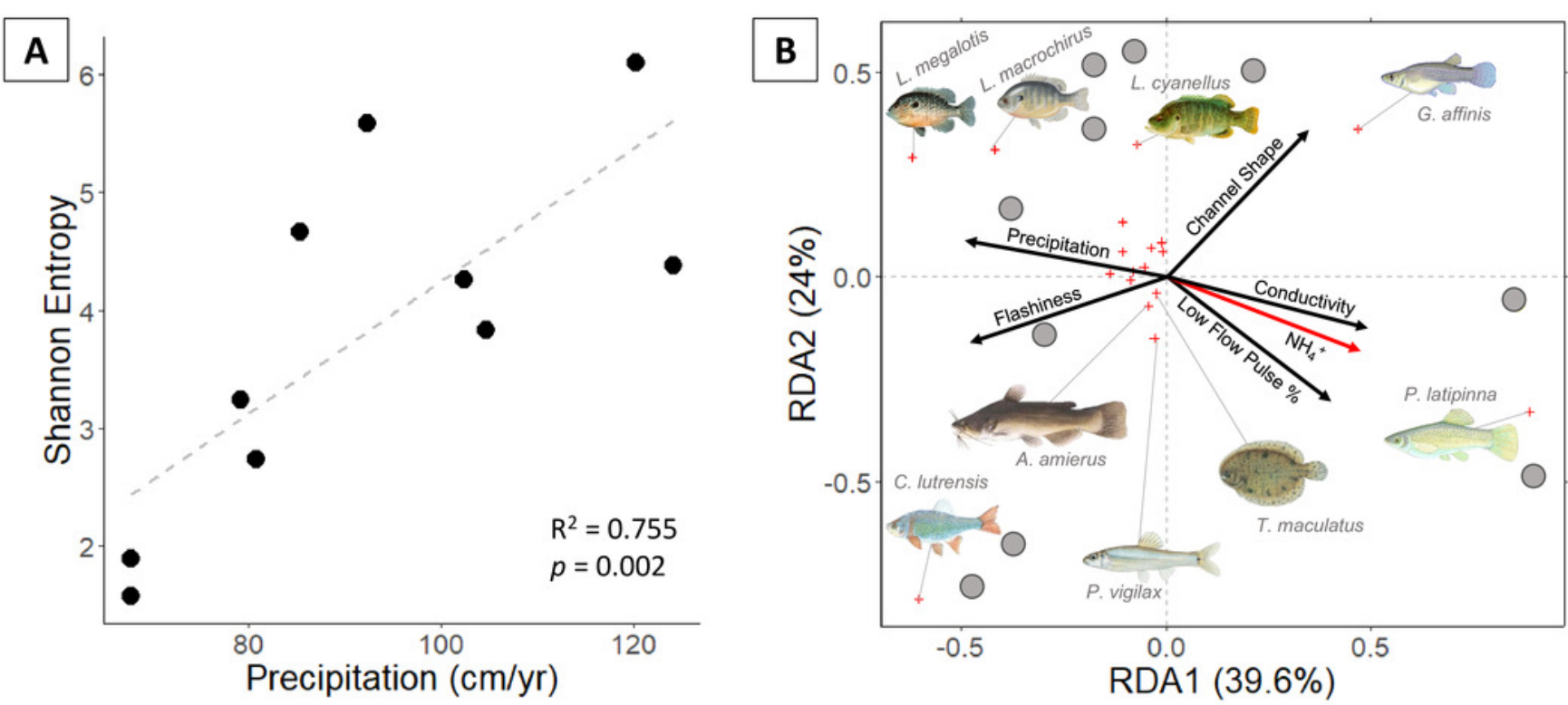
Figure 3

(A) Invertebrate diversity plotted against annual precipitation (cm/yr) (B) Invertebrate community ordination using Hellinger transformation and redundancy analysis.

Axes labels display the proportion of the variance explained as a percentage. Sites are represented by grey circles. Species are represented by red crosses, with species labels and reference images added to outer members. Environmental variables are shown in arrows and the significant ones are presented in red.
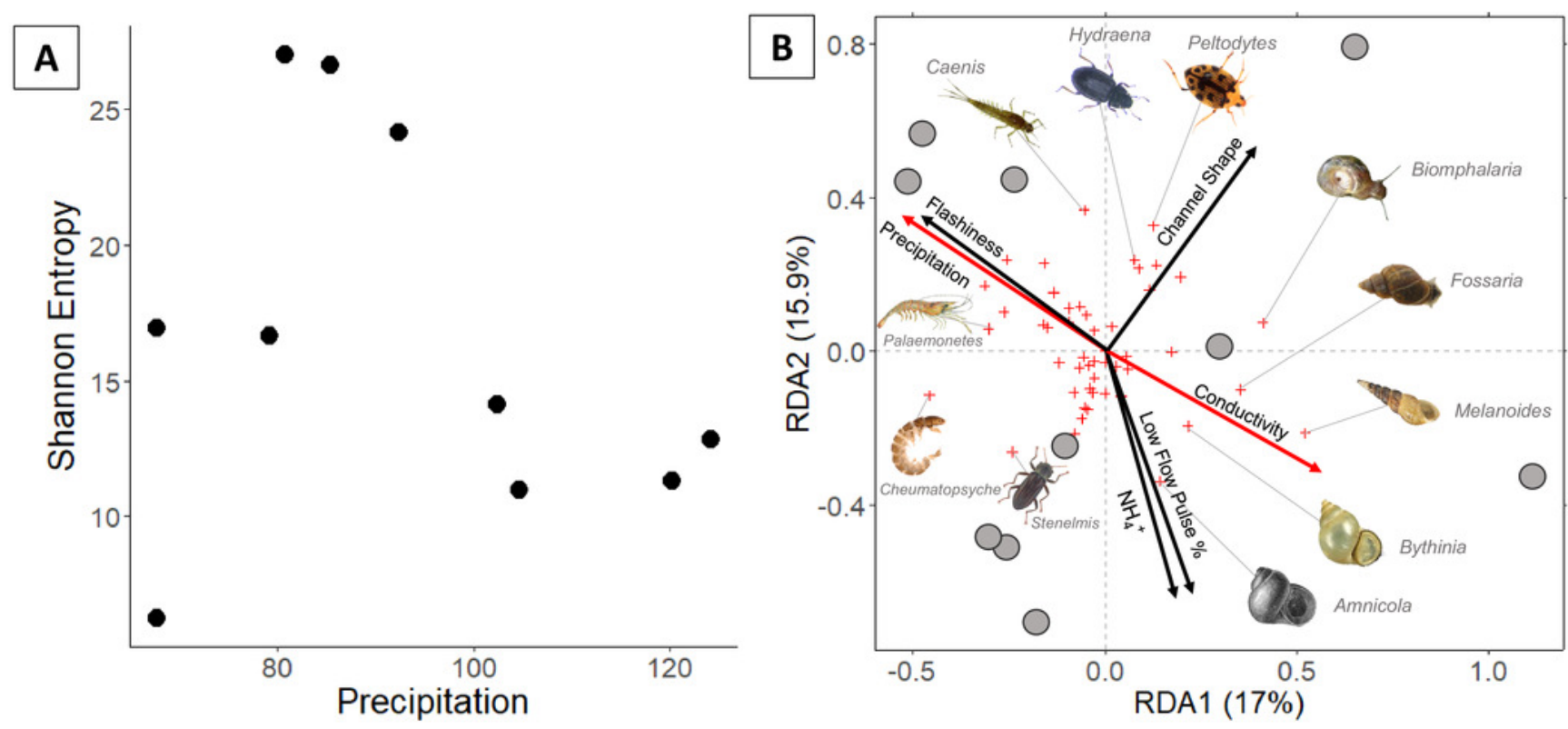


\section{Table $\mathbf{1}$ (on next page)}

Univariate regression summary statistics and multiple regression relationships predicting fish and invertebrate Shannon entropy using environmental predictors.

* denotes a p-value $<0.05$ or an $\Delta \mathrm{AICC}<2$. 


\begin{tabular}{|c|c|c|c|c|c|c|c|}
\hline Response & Input & Slope & $\mathbf{R}^{2}$ & F-stat & df & p-value & $\begin{array}{c}\text { Multiple } \\
\text { Regression }\end{array}$ \\
\hline Shannon $_{\text {Fish }}$ & Precipitation & 0.056 & 0.576 & 10.885 & 2 & $0.011 *$ & $+*$ \\
\hline Shannon $_{\text {Fish }}$ & Flashiness & 1.430 & 0.038 & 0.316 & 2 & 0.589 & + \\
\hline Shannon $_{\text {Fish }}$ & Channel Shape & 0.113 & 0.069 & 0.597 & 2 & 0.462 & + \\
\hline Shannon $_{\text {Fish }}$ & Low Flow Pulse \% & -0.083 & 0.222 & 2.281 & 2 & 0.169 & - \\
\hline Shannon $_{\text {Fish }}$ & $\mathrm{NH}_{4}{ }^{+}$ & -13.221 & 0.326 & 3.877 & 2 & 0.084 & - \\
\hline Shannon $_{\text {Fish }}$ & Conductivity & -0.920 & 0.413 & 5.636 & 2 & $0.045^{*}$ & - \\
\hline Shannon $_{\text {Invert }}$ & Flashiness & 8.651 & 0.061 & 0.517 & 2 & 0.493 & + \\
\hline Shannon $_{\text {Invert }}$ & Precipitation & -0.085 & 0.057 & 0.487 & 2 & 0.505 & - \\
\hline Shannon $_{\text {Invert }}$ & Low Flow Pulse \% & -0.489 & 0.336 & 4.056 & 2 & 0.079 & $-*$ \\
\hline Shannon $_{\text {Invert }}$ & $\mathrm{NH}_{4}^{+}$ & -2.519 & 0.001 & 0.004 & 2 & 0.950 & - \\
\hline Shannon $_{\text {Invert }}$ & Conductivity & -0.884 & 0.017 & 0.135 & 2 & 0.723 & - \\
\hline Shannon $_{\text {Invert }}$ & Channel Shape & -0.899 & 0.193 & 1.917 & 2 & 0.204 & - \\
\hline
\end{tabular}

